\title{
V3DM+: BIM interactive collaboration system for facility management
}

\author{
Wan-Li Lee ${ }^{1}$, Meng-Han Tsai ${ }^{2 *}$, Cheng-Hsuan Yang ${ }^{3}$, Jhih-Ren Juang ${ }^{1}$ and Jui-Yu Su ${ }^{1}$
}

\begin{abstract}
Background: Facility management (FM) is an important phase in the building lifecycle. Although building information modeling (BIM) technology has been widely used in the design and construction phase, efforts to transfer information to the FM phase are still in the nascent stage. A good BIM-to-FM tool should be able to inherit and integrate the building information built in the design and construction phase as well as be able to provide a platform for managers to browse the information, discuss potential problems, and arrange maintenance work.

Methods: In this research, a BIM interactive collaboration system for FM is designed and implemented. Two modules were developed for optimizing the BIM system in the FM phase: the data arrangement module, which has functionalities of data importing and processing, and the data presentation module, which provides functionalities of data revealing and collaboration.

Result: From the results of an accessibility analysis, we verified that the developed system, V3DM+, can be implemented on real projects. Managers can use V3DM+ to support operation and maintenance of buildings. Moreover, a web-based platform allows users to manage facilities intuitively without investing on professionals or specialized software.

Concluding: The proposed system, V3DM+, provides a data arrangement module to integrate building information constructed by various types of commercial software and present them in a visual manner. The user can find the required information, initiate a discussion on an issue, or arrange operation and maintenance tasks directly on this system.
\end{abstract}

Keywords: Building information modeling, Facility management, Interactive platform

\section{Background}

Facility management is an important phase in the lifecycle of a building. The operation and maintenance costs of a building are considerably greater than the construction costs (Gallaher et al. 2004). By providing appropriate project information to facility managers, these costs can be greatly reduced. In 1983, the National Academy of Sciences first noticed the importance of useful facility management data for operation and maintenance of buildings (Scarponcini 1996).

In the past, facility managers used $2 \mathrm{D}$ graphics to acquire basic information. However, 2D graphics contain several symbols that only professionals would

\footnotetext{
* Correspondence: menghan@ntu.edu.tw

${ }^{2}$ Center for Weather Climate and Disaster Research, National Taiwan University, Taipei, Taiwan

Full list of author information is available at the end of the article
}

understand, thus leading to difficulty in interpretation of the information for managers (Tsai et al. 2014a). Currently, many researchers have been attempting to implement building information modeling (BIM) for facility management (FM). BIM visually presents spatial data through 3D models, which can enhance managers' level of comprehension of the information (Tsai et al. 2014b). The following sections review studies on BIM for FM and the challenges in using BIM in the operation and maintenance phase.

Yu et al. (2000) developed a framework for computerintegrated FM and pointed out that the project data should be selectively transferred into the building FM phase. Vanlande et al. (2008) developed an extension of BIM technology, which allowed the creation of an information system dedicated to the entire building lifecycle. A visual BIM-based approach for evaluating the coverage 
of a CCTV system in public areas associated with a building was developed by Chen et al. (2013). Lee et al. (2015) conducted a case study of applying BIM coordination technology to a high-speed rail station. Edwards et al. (2015) attempted to apply game engine technology to BIM to build a collaborative and interactive platform for end users of the building. YouBIM, a spin-off international building information modeling service firm, developed a software named YouBIM, which provides a cloud-based solution to manage the building activities in a simple way in the FM phase (YouBIM 2015).

Data inheritance and integration is one of the big challenges in implementing BIM technology for FM. BIM has been widely used in the design (Lee et al. 2014) and construction (Chen et al. 2015) phases. Although several types of software exist in the market for architects and constructors to build BIM models, interoperability of the software is limited. Therefore, data transformation and integration is difficult (Wetzel et al. 2015). To address the issue of how to fully utilize existing data in the FM phase, some standards have been developed for information exchange. The Industry Alliance for Interoperability (IAI) developed a data transformation standard, called the Industry Foundation Classes (IFC), which allows exchange of 3D models and information data among specific BIM tools (NIST 2007). According to buildingSMART, which publishes the IFC data model standard, IFC can currently be supported around 150 software applications worldwide (buildingSMART 2015). Furthermore, East (2007) reported in Construction Operations Building Information Exchange (COBIE): Requirements Definition and Pilot Implementation Standard that the development team of the National Building Information Model Standard (NBIMS) released a standard known as COBIE for selecting information generated in the design and construction phase and providing the information to the operation and maintenance phase.

Besides data inheritance and integration, the design of existing BIM tools is another challenge. Existing BIM tools are typically designed for the construction industry and have the main functionality of model and data construction, with user interfaces designed to support this activity. However, FM involves multidisciplinary activities, and hence, a BIM tool for FM should be able to provide diverse functionalities, such as visualization, analysis, and discussion (Becerik-Gerber et al. 2012; Singh et al. 2011).

In summary, BIM is an advanced approach for the architecture, engineering, and construction (AEC) industries that aids in the exchange and interoperability of information for design, construction, and management (Eastman et al. 2008). BIM technology has been successfully used in the design and construction phase of the AEC industry. However, as Wetzel et al. (2015) described, "with all the success that BIM has experienced during the design and construction phase, efforts to transfer information to the facility lifecycle phase is in its infancy." Moreover, some problems remain to be resolved for optimizing BIM technology for FM. Therefore, this research aims to develop a system that can inherit and integrate building information from the design and construction phase and utilize the information in FM. In addition, a visual interactive platform is designed for data collaboration, which allows users to browse through the facility information, discuss a facility's potential problems, and arrange operation or maintenance personnel.

\section{Research goal}

This research aims to develop a BIM interactive collaboration system for FM. FM plays a critical role in the life cycle of a building because facilities are complicated and need long-term maintenance. No software or BIM tools thus far can completely integrate the 3D models and information data of facilities in order to specifically focus on the development of a computer-aided system for FM. Such a system should achieve the following goals:

1. The system should be able to integrate the 3D models built by different BIM tools and data from different types of software, which may have different file formats.

2. The user should be able to intuitively use this system. With this feature, users' willingness to implement this system will be elevated because they do not need to invest in professionals or authorized software.

3. The user should be able to find information about a facility in a fast and efficient way, and the system should allow them to instantly initiate a discussion. By this feature, users can interact with each other instantly when a problem is identified.

\section{BIM interactive collaboration system}

In this research, a BIM interactive collaboration system was developed, which can help administrators integrate the 3D models and information obtained from constructors and discuss issues related to facilities on a discussion platform. In the following sections, we discuss the modules of the system and their functionalities.

This system includes two main functions: data arrangement and data presentation (Fig. 1). The data arrangement module comprises functionalities for data importing and processing. The data presentation module reveals the processed data and provides an online platform for users to discuss issues related to a facility and assign tasks to concerned personnel. 


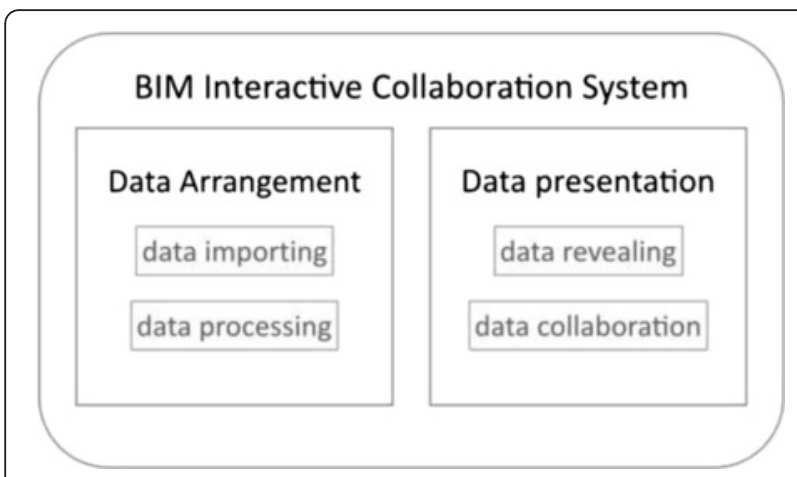

Fig. 1 BIM interactive collaboration system with two modules: data arrangement and data presentation

\section{Data arrangement module}

The data arrangement module consists of two phases: data importing and data processing. In the data import phase, the facility models built by different software, which may be in different formats, are transformed into a unified format. The imported data are then integrated and stored in a database in the data processing phase.

\section{Data importing}

In the data import phase, users can import the 3D models and information data. The files from different BIM tools will be of various formats and sometimes are not compatible. Thus, this system provides an Application Programming Interface (API) library for converting all the files into the same format. In addition, we also developed a $3 \mathrm{D}$ model converter for non-BIM projects that may not contain 3D-model files, such as ArcGIS and ArcInfo for the GIS files.

To unify the file format, we provide a data-converting API library, using which the 3D models can be exported to the FBX file format. In the conversion process, a specific ID is assigned to each object and its related information. As a result, the data can be integrated precisely and the user can easily interact with objects and information data.

\section{Data processing}

In the data processing phase, the imported 3D models and information data are processed (Fig. 2). Each BIM model is built by the respective department and so differences may exist between the models. The imported models are integrated and regulated to a central model, and a core database is used to store the imported information data. Every object in the model is linked with its related information data by the specific ID created in the data-importing phase (Fig. 3). For instance, a water pipeline model is linked with information regarding its location, diameter, materials, and so on.

In addition, this system has an update management center for managing the modified data. In the construction phase, a facility may be adjusted in accordance with a revised construction plan. In the management phase, a facility may be replaced because of damage or for updating. To append these new data to the existing data accurately, the updating management central first integrates the modified model into a temporary model, and then sets an ID for both the models and their related information data, which is the same as the ID of the existing data.

\section{Data presentation module}

The data presentation module comprises two functionalities: data revealing and data collaboration. The data revealing function presents the data in an intuitive and visual manner. We developed an interactive platform that provides data collaboration functions for the users to discuss related issues and then allows the manager to assign tasks to concerned personnel.

\section{Data revealing}

Facilities in the central model are demonstrated in a 3D environment and information about each object is

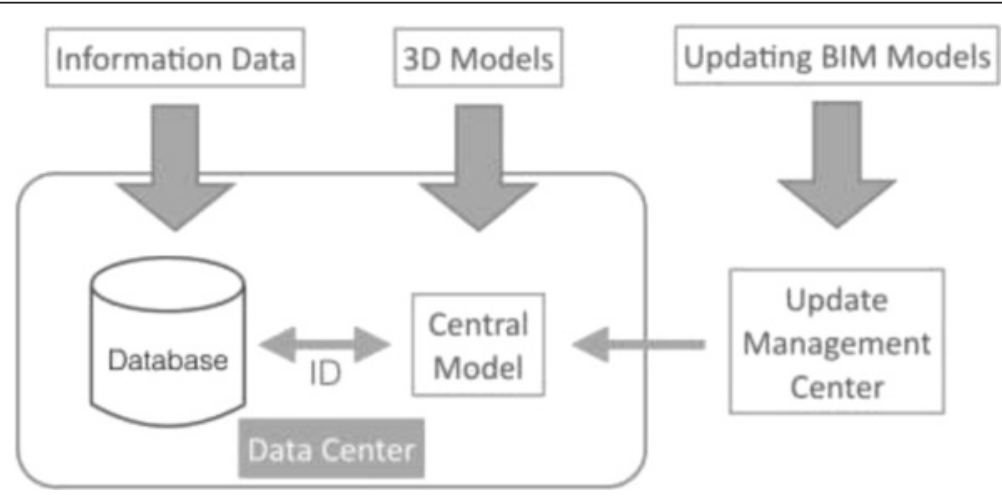

Fig. 2 Data processing and integration of imported 3D models and information data 


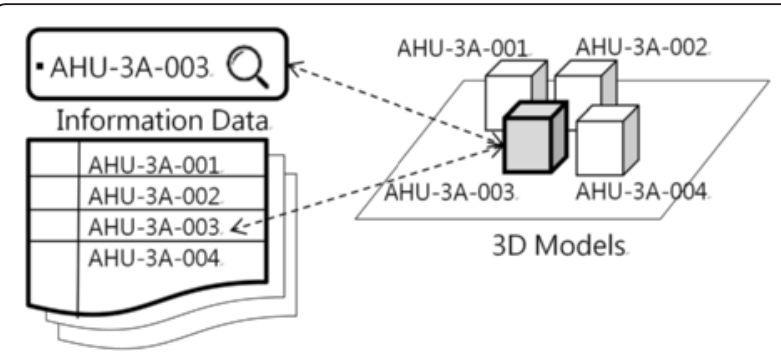

Fig. 3 Information data and 3D models linked with the specific ID so that the user can find an object's information data by clicking the 3D models or searching by its ID

connected to its 3D model. The user can choose to walk in the $3 \mathrm{D}$ environment, with a first-person perspective or browse through the whole 3D model from a thirdperson perspective to find the facility they want to inspect and obtain related information. In addition, the user can also find the facility's relative position in the virtual environment by searching its features, such as ID, utilities, materials, or any other imported properties related to the facilities.

In this study, we use a game engine to display the 3D environment. A game engine can provide a realistic 3D rendering scene and users can navigate in the virtual environment without restrictions. Furthermore, the powerful real-time 3D graphics and networking properties of a game engine provide an intuitive interface for the user (Petri et al. 2014). By using a game environment, a facility manager who is not familiar with the complicated operation of BIM tools can intuitively browse through the models. The information data can be queried when required. In addition, we use a filter to sort the information data of the objects by their categories, utilities, and location, allowing users to search for facility information through a hierarchical menu. For instance, if the user wants to know the pipe diameter of an airconditioner on the 5 th floor, they can get this information by searching the keywords: "air-conditioner", "pipeline", and " 5 th floor".

\section{Data collaboration}

Data collaboration not only helps a constructor discuss issues in the design phase but also allows a facility manager to assign maintenance tasks to workers. An obstacle to facility design discussion is that various facilities exist in a building, involving different kinds of professionals such as air-conditioner technicians and mechanical, electrical, and plumbing (MEP) mechanics. This system provides a collaborative platform for professionals to discuss issues related to equipment in the design phase. In the management phase, managers can navigate in the $3 \mathrm{D}$ environment to identify broken equipment and obtain the responsible manufacturer's communication information to assign a maintenance task. For equipment that has periods of effectiveness, such as extinguishers, the system will automatically inform managers and the manufacturers a week before the expiry dates.

\section{User interface design}

This system has a web-based user interface that does not require any authorized software. The user interface includes a header and a work zone. The header contains the project name and a mode switcher, which is for switching between the different function modes of this system. The work zone is divided into four viewers: system utilities viewer, main viewer, information viewer, and detail viewer. The system utilities viewer is revealed or concealed depending on the function chosen by the user. The $3 \mathrm{D}$ models are displayed in the main viewer. The information viewer shows the ID and the name of the objects revealed in the $3 \mathrm{D}$ environment. In the data browsing mode, the detail viewer displays the detailed information of the selected object. In the issue discussion mode, the detail viewer unfolds the historic and ongoing discussion of issues related to the selected object, and the user can start a new issue to discuss if necessary.

\section{System implementation}

We developed a BIM interactive collaboration platform, named $\mathrm{V} 3 \mathrm{DM}+$, for assisting FM. To implement the proposed system, we combined HTML 5 and Unity 3D, a game engine that supports $3 \mathrm{D}$ environments, virtual navigation, and a web player. HTML 5 is used for visualizing information data and handling discussions. Unity $3 \mathrm{D}$ directly displays the 3D models on the website. By applying Unity 3D and HTML 5, building managers can use this system without considering hardware limitations. The following sections will introduce the actual user interface and operating procedure for V3DM+.

\section{System structure}

As mentioned in Section 3, the system we developed has two modules, having two phases each, to process the building data. Figure 4 shows the workflow of these four phases. In data importing, models and information data are imported into this system manually. By converting the data into the same file formats through API, all the data are stored in the data center. All data models are then displayed in a 3D environment, which is built on a game engine, while the information data can be accessed through a website-based interface. In addition, the issue discussions that are ongoing or completed and task assignment records generated from the data collaboration phase are stored as real-time data. These data are imported into the system automatically and instantaneously as they are generated. 


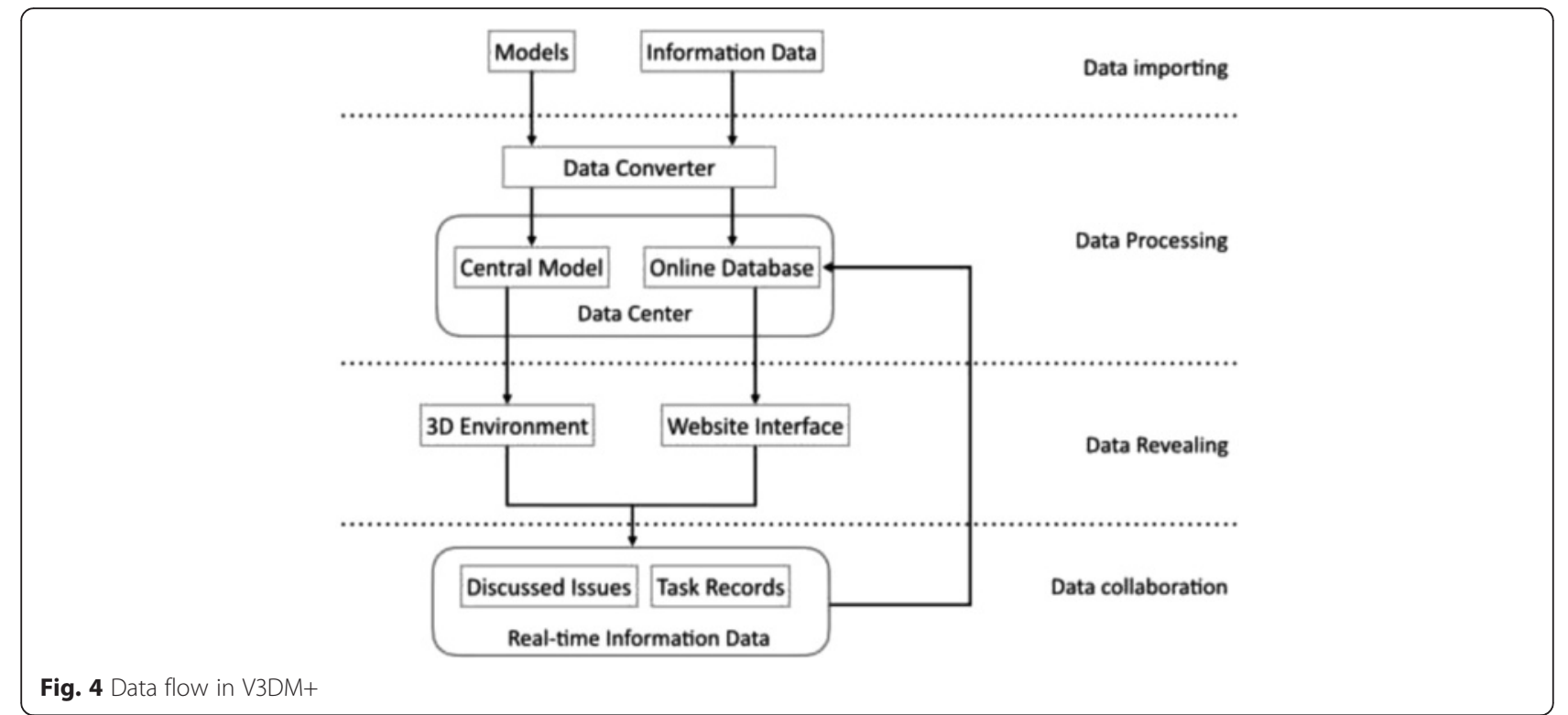

The V3DM+ system is extensible for developing varied BIM scenarios and applications. Figure 5 shows the model-view-controller architecture (MVC) and technology of the V3DM+ system. The web services in Model has a programing interface to access BIM models based on JSON data format and internet HTTP protocol. Thus, the interface provides extensibility of user scenario development and integration of cross-platform applications, such as mobile, web, and other application platforms, in order to provide interoperable services and to adapt to potential and varied BIM scenarios. This implementation follows service-oriented architecture (SOA), which provides services via a visible communication protocol on network rather than the service provided by any vendor or product. In this article, the $\mathrm{V} 3 \mathrm{DM}+$ provides a web-based scenario for facility management, established on the services provided by Model. View and Controller are implemented through a web frontend design.

Data importing and data processing are implemented in Model, which stores BIM models and provides interfaces for accessing BIM models. The data conversion applications are responsible for data importing, which converts BIM models into the formats defined in the database (Fig. 5). The data conversion applications are implemented using the API, which depends on BIM model formats and tools, such as Revit and ArchiCAD. The API encapsulates data processing procedures into

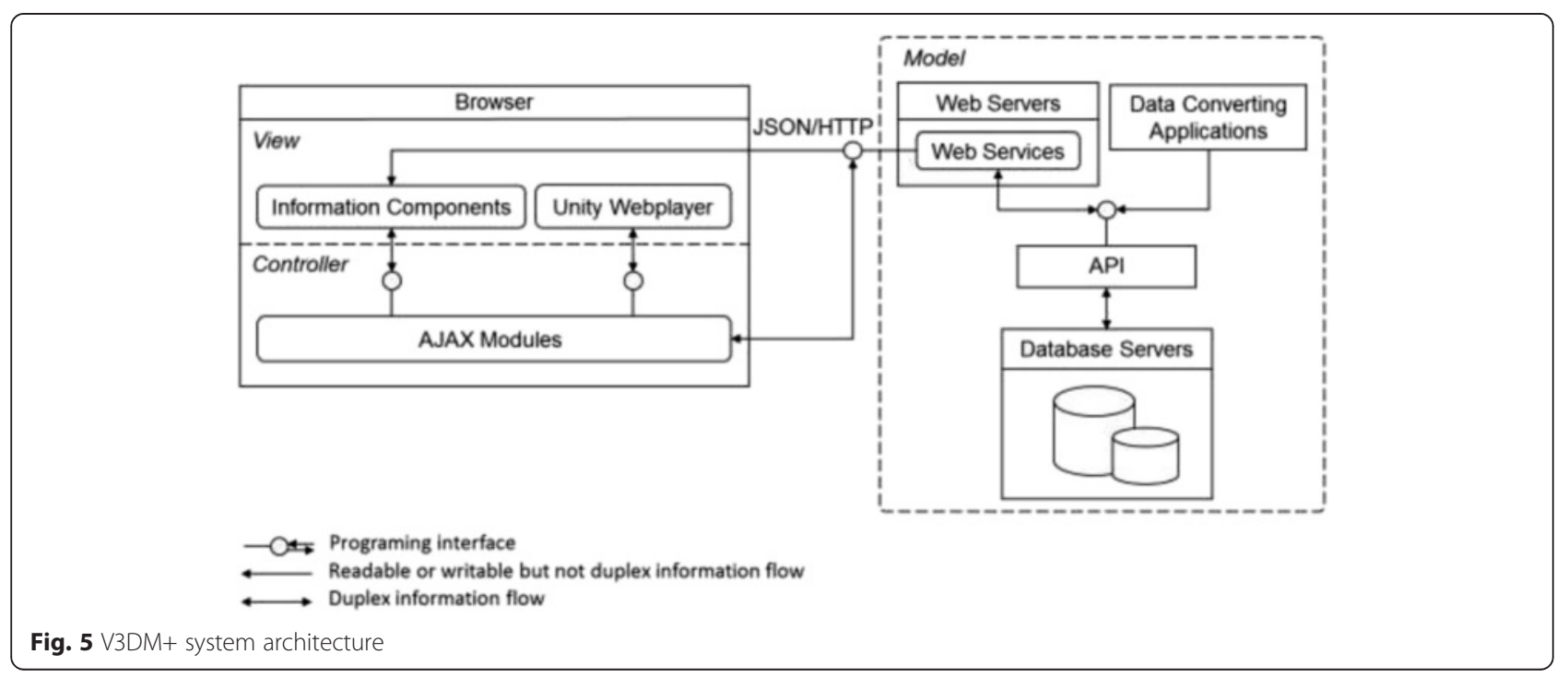


simplified interfaces that make easier to process the BIM models into the database. The procedures establish relations between information data and 3D models in the database. These relations are retrieved and applied for data revealing and data collaboration. Relation retrieving is the fundamental functionality of the web services, which implement the high-level interface for SOA usage.

Data revealing and data collaboration are performed in a rich information application (RIA) framework for web application. Users can reveal BIM models from interactive 3D elements and information grid tables, and they can collaborate with their colleagues in facility management scenarios provided by the system. The user interface is implemented with HTML object tags including a Unity 3D web player and information components. The web player displays a 3D environment, which is interactive through the physical inputs, and can communicate with other modules through Controller. The web player is deployed by Unity Engine, a game engine that supports web deployment. The information components define UI templates to display the information other than 3D models.

Data collaboration is implemented using Controller along with VIEW. Controller consists of AJAX modules, which coordinate the physical inputs and the components in VIEW and SOA services in Model. The modules describe how the SOA services organize the collaboration scenario in facility management. The scenario connects the users to work collaboratively on the same problem-solving task.

\section{User interface}

The user interface of V3DM+ is divided into five parts: the mode switcher, main viewer, information viewer, detail viewer, and system utilities viewer (Fig. 6). The user can choose a function by switching the mode at the top of the screen. The main viewer displays the $3 \mathrm{D}$ rendering models of an entire building and its facility equipment. On the left side of the 3D main viewer, there is a toolbox for assisting the user in browsing the models. The system utilities viewer is either revealed or concealed depending on the function the user chooses. The information viewer lists the ID and the name of the objects displayed on the 3D environment. The detail viewer shows the details of an object on the right side of the screen when the user clicks the object in the 3D model or in the information viewer. For instance, if the user chooses the air-conditioner on the fifth floor, the highresolution information viewer will list the airconditioner's detailed information, such as its size, location, useful life, and related files. In addition, the detail viewer plays a different role in the issue discussion mode. In this mode, a user who identifies a problem about a facility can create a discussion for an issue in the high-resolution information viewer. In addition, appropriate personnel can interact with each other to determine a solution to the problem and the manager can assign maintenance tasks to the person in charge directly on this platform.

In summary, the web-based user interface of V3DM+ allows users to browse both 3D models and information data on the web browser easily. In addition, with this system, users can interactively discuss issues related to facilities with each other online. For solving maintenance problems, users can directly contact the person in charge and assign tasks.

\section{Operating procedure}

This section introduces the procedure for using V3DM+ (Fig. 7). Before executing the system, the user imports the information data and models into the data arrangement module manually so that the system can present

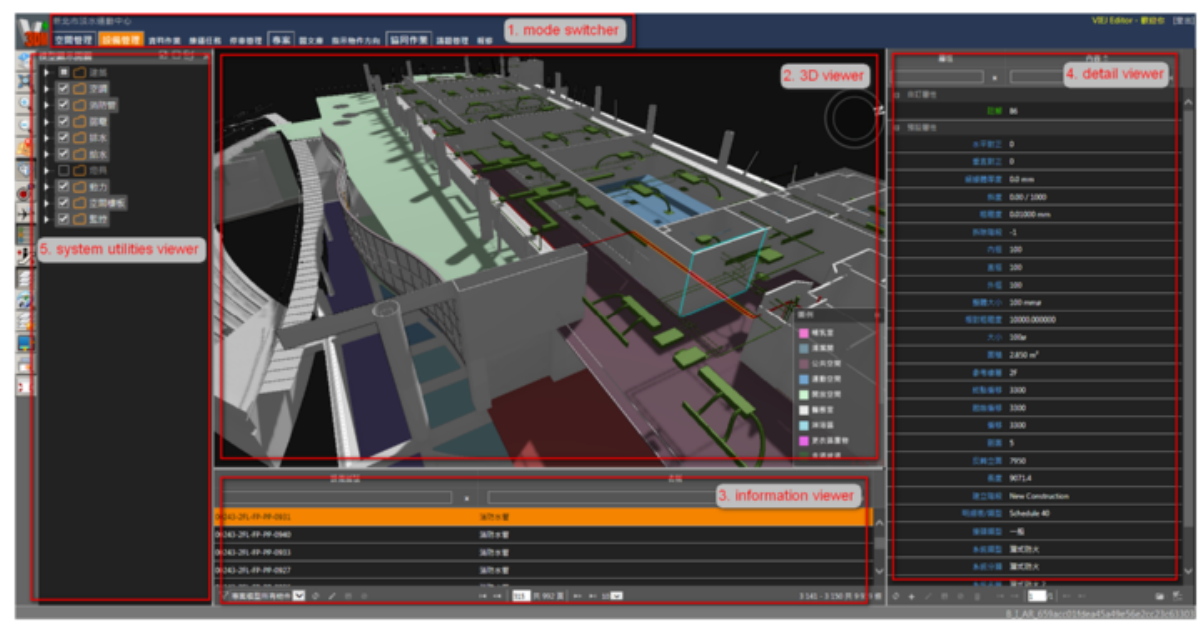

Fig. 6 Five main parts of the system: mode switcher, 3D viewer, information viewer, detail viewer, and system utilities viewer 


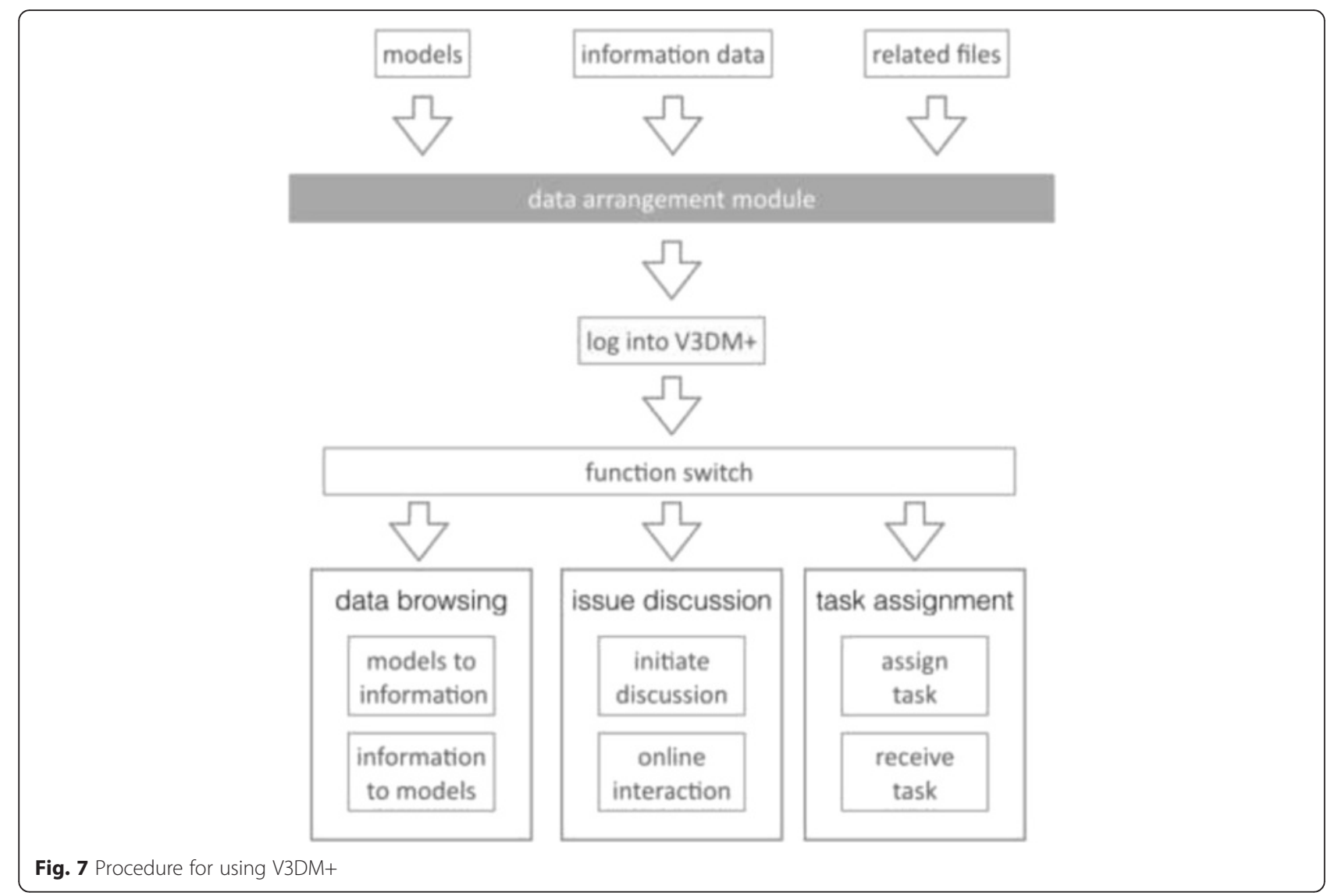

those data in a realistic rendering environment. The user can also attach files such as installation instructions or operation manuals to their related models. Next, the user logs in to the system through a website browser such as Internet Explorer, Google Chrome, or Safari. After launching the system, the user can choose to browse the facility data, initiate a discussion, or assign a task by selecting the function using the mode switcher.

When the data browsing mode is chosen, the user can browse the models in the 3D environment with a firstperson perspective or a third-person perspective. The information data are displayed when an object in the model is clicked. The user can also search for a facility in the 3D model by entering its ID, utilities, or location. The files related to the facilities can also be downloaded (Fig. 8).

In the issue discussion mode, the user can initiate a discussion on the system. Since the information data and the 3D models are all integrated in this system, the user can directly discuss issues about facilities, such as spatial planning or facility management. Moreover, $\mathrm{V} 3 \mathrm{DM}+$ supports multiple log-ins, thus allowing appropriate personnel to simultaneously discuss the issues online in real time without requiring a face-to-face meeting.
In the task assignment mode, a manager can assign a task to maintenance personnel through this system (Fig. 9). First, the manager identifies a facility in the 3D model or simply by searching for its name or ID. Second, the manager adds a new task based on the model and inputs a problem description about the facility that requires maintenance. Finally, the system sends a message to the personnel in charge. After receiving the message, the personnel can log in to V3DM+ and obtain information about the broken facility, and then perform the assigned maintenance task.

\section{Accessibility analysis}

An accessibility analysis was conducted to test the developed facility management system using a real project of the Tamsui Civil Sports Center (TSSC) as a case study. We first analyzed the management demands of the TSSC. Second, we optimized and implemented V3DM+ on the sports center by taking completed construction reports and models as the data source. Finally, we received results and derived ideas from the case study.

\section{Demand analysis of the TSSC}

The TSSC is a sports center located in New Taipei City, in the north of Taiwan. The TSSC building has five 


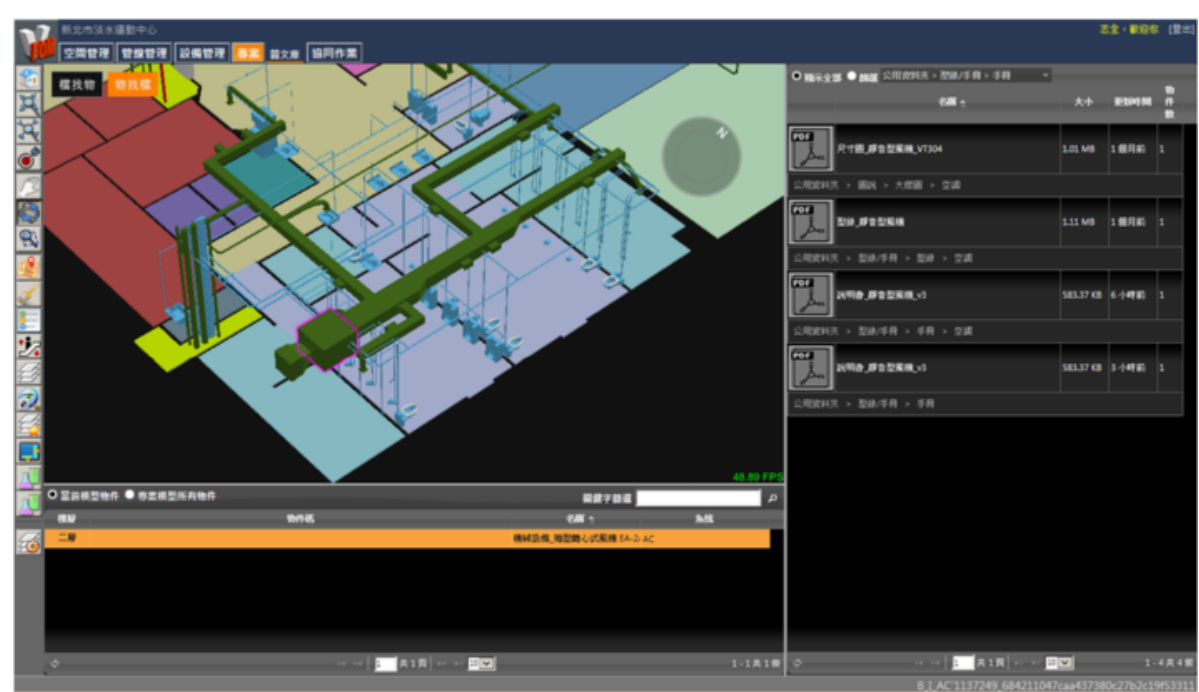

Fig. 8 Downloading of related files when a facility is selected

floors above ground and two levels below ground. A large variety of facilities make maintenance management of the TSSC complicated. The TSSC includes essential facilities such as the MEP, fire, and air-conditioning systems. In addition, management of sports facilities, arrangement of cleaning staff, and placement of patrol officers are the operational issues that need consideration.

Sports center management is more complicated than that of normal buildings because of the high number of facilities that require maintenance, such as treadmills, badminton courts, or swimming pools. Furthermore, the users of a sports center can be anyone living near it rather than a fixed group of people, thus increasing the difficulty of maintenance. Therefore, considering a sports center for the case study is a worthy option.

To implement V3DM+ for the sports center, we first listed all the spaces in the TSSC and sorted by location. The spaces were then analyzed according to six operational management terms: site rental, site maintenance, equipment rental, equipment maintenance, cleaning, and regular inspection (Table 1). After the analysis, we found that sports-related spaces typically needed management

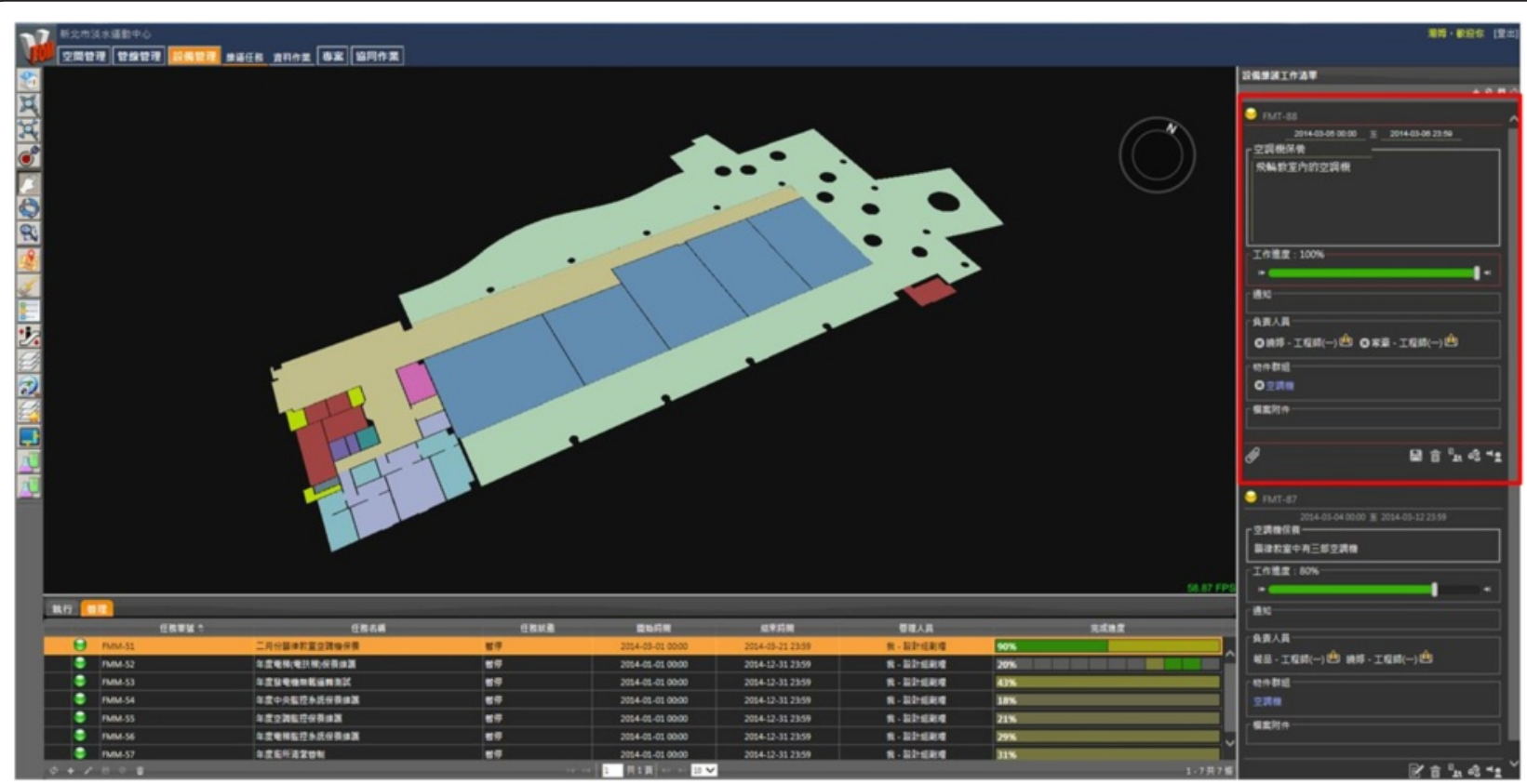

Fig. 9 Assignment of a task by a manager to maintenance personnel on the system 
Table 1 Spaces in the TSSC analyzed according to site rental, site maintenance, equipment rental, equipment maintenance, cleaning, and regular inspection

\begin{tabular}{|c|c|c|c|c|c|c|c|}
\hline \multirow[t]{3}{*}{ Floor } & \multirow[t]{3}{*}{ Facilities } & \multicolumn{6}{|c|}{ Operational arrangement } \\
\hline & & \multicolumn{2}{|l|}{ Site } & \multicolumn{2}{|c|}{ Equipment } & \multirow[t]{2}{*}{ Cleaning } & \multirow[t]{2}{*}{ Regular inspection } \\
\hline & & Rental & Maintenance & Rental & Maintenance & & \\
\hline \multirow[t]{5}{*}{ B1 } & Swimming pool & V & V & V & V & V & V \\
\hline & Spa & & V & & & V & V \\
\hline & Stores & & & & & V & \\
\hline & Infirmary & & & & & V & \\
\hline & Life guard office & & & & & V & \\
\hline \multirow[t]{4}{*}{ B2 } & Parking lot & V & & & & V & \\
\hline & Machine room & & & & & V & V \\
\hline & Machine room (swimming pool) & & & & & V & V \\
\hline & Water storage tank & & & & & & V \\
\hline \multirow[t]{7}{*}{$1 \mathrm{~F}$} & Ticket office & & & & & V & \\
\hline & Stores & & & & & V & \\
\hline & Rock climbing area (outdoor) & V & V & & V & V & \\
\hline & Infirmary & & & & & V & \\
\hline & Office \& Conference room & & & & & V & \\
\hline & Lobby & & & & & V & \\
\hline & Restaurant & & & & & V & \\
\hline \multirow[t]{7}{*}{$2 \mathrm{~F}$} & Outdoor platform & & & & & V & \\
\hline & Aerobics room & V & V & & & V & \\
\hline & Fitness training room & V & V & V & V & V & \\
\hline & Spinning bike room & V & V & & V & V & \\
\hline & Play room (for children) & & V & & V & V & \\
\hline & Chess room & & & V & & V & \\
\hline & Rest area & & & & & V & \\
\hline \multirow[t]{5}{*}{$3 F$} & Comprehensive courts & V & V & V & V & V & \\
\hline & Table tennis room & V & V & V & V & V & \\
\hline & Machine room & & & & & V & V \\
\hline & Instrument room & & & & & V & \\
\hline & Rest area & & & & & V & \\
\hline \multirow[t]{3}{*}{$4 \mathrm{~F}$} & Billiard room & V & V & V & & V & \\
\hline & Rest area & & & & & V & \\
\hline & Auditorium & & & & & V & \\
\hline $5 F$ & Badminton court & V & V & V & V & V & \\
\hline \multirow[t]{3}{*}{$5 F$} & Multifunctional courts (outdoor) & V & V & & & V & \\
\hline & Racquetball court & V & V & V & V & V & \\
\hline & Shower compartment & & & & & V & \\
\hline \multirow[t]{5}{*}{$\mathrm{R}$} & Machine room (elevators) & & & & & V & V \\
\hline & Machine room (air-conditioning) & & & & & V & V \\
\hline & Converter room & & & & & V & V \\
\hline & Electricity generator & & & & & V & V \\
\hline & Water storage tank & & & & & & V \\
\hline
\end{tabular}


of site rental and site maintenance. All the machine rooms in the TSSC needed regular inspections. In addition, except for water tanks, all the spaces needed arrangement of staff for environment cleaning.

\section{Optimization and implementation of V3DM+ for TSSC}

The first step in the implementation of V3DM+ for the TSSC is importing BIM models, including information data and 3D models, into the data arrangement module. For this step, we took the completed construction reports and existing BIM models of the TSSC as the data source. Via the API library, the 3D models were transformed into FBX files, and the information data were stored in a database and connected to the 3D models by specific IDs. Related files, such as equipment user manuals, were also attached to the BIM models.

After data importing, the system was improved to meet the management demands of the sports center. The task assignment function was improved for a manager to arrange cleaning staff and regular inspectors (Fig. 10). The inspectors can log into V3DM+ to update the situations of the facilities. In addition, an online reservation function was added to the system so that people who want to rent sports sites or equipment can reserve them using this system (Fig. 11).

\section{Results}

A case study of the real project was conducted to validate the accessibility of V3DM+, a BIM-based system for FM. The results confirm the feasibility of implementation of the proposed system.

The manager of the sports center can use V3DM+ to directly browse through the data of all facilities in the sports center, which increases the efficiency of facility maintenance. For example, without V3DM+, the manager needs to physically find a broken pipeline, which may often be installed in the ceiling, in order to acquire its specifications. However, with V3DM+, the manager can obtain all the information about the broken facility on $\mathrm{V} 3 \mathrm{DM}+$ and contact the manufacturer directly.

For the operational management, those who wish to rent equipment or space can log into $\mathrm{V} 3 \mathrm{DM}+$ and make an online reservation (Fig. 12). The manager can also check the reservation application in the system. Moreover, the manager can arrange a cleaning task and regular inspection after checking the facilities through visualization. During task processing or after completing a task, inspectors and cleaning staff can upload the task progress into $\mathrm{V} 3 \mathrm{DM}+$ for the manager to confirm (Fig. 13).

\section{Discussion and evaluation}

In this study, we developed a BIM interactive collaboration system, V3DM+, for FM. Through an accessibility experiment on a real project, we verified that V3DM+ can greatly contribute to FM. However, some limitations exist for implementing this system in a real case.

\section{Contributions}

This research proposed an innovative system for FM and made efforts in the following aspects:

\section{A universal system for facility management}

This system can integrate all the data built by different types of BIM tools manually. V3DM+ provides an API

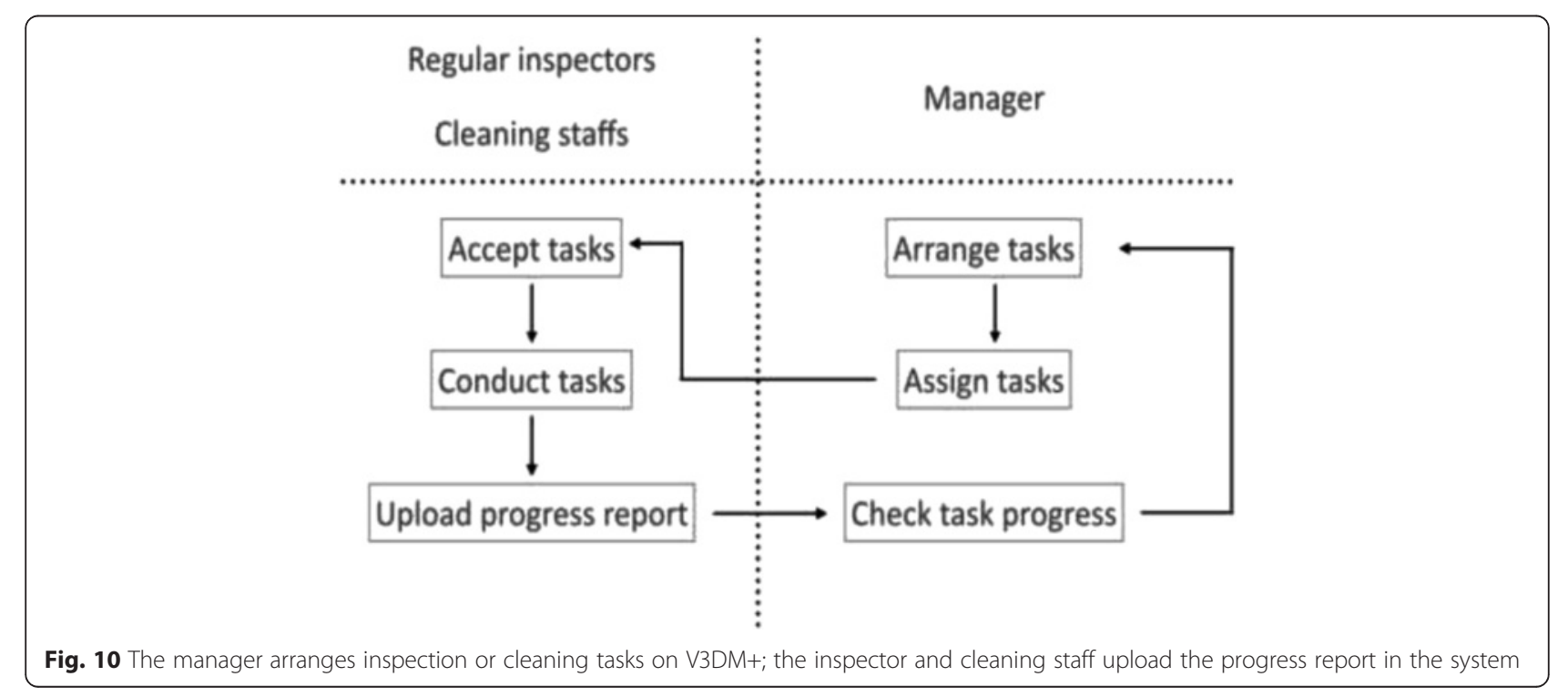




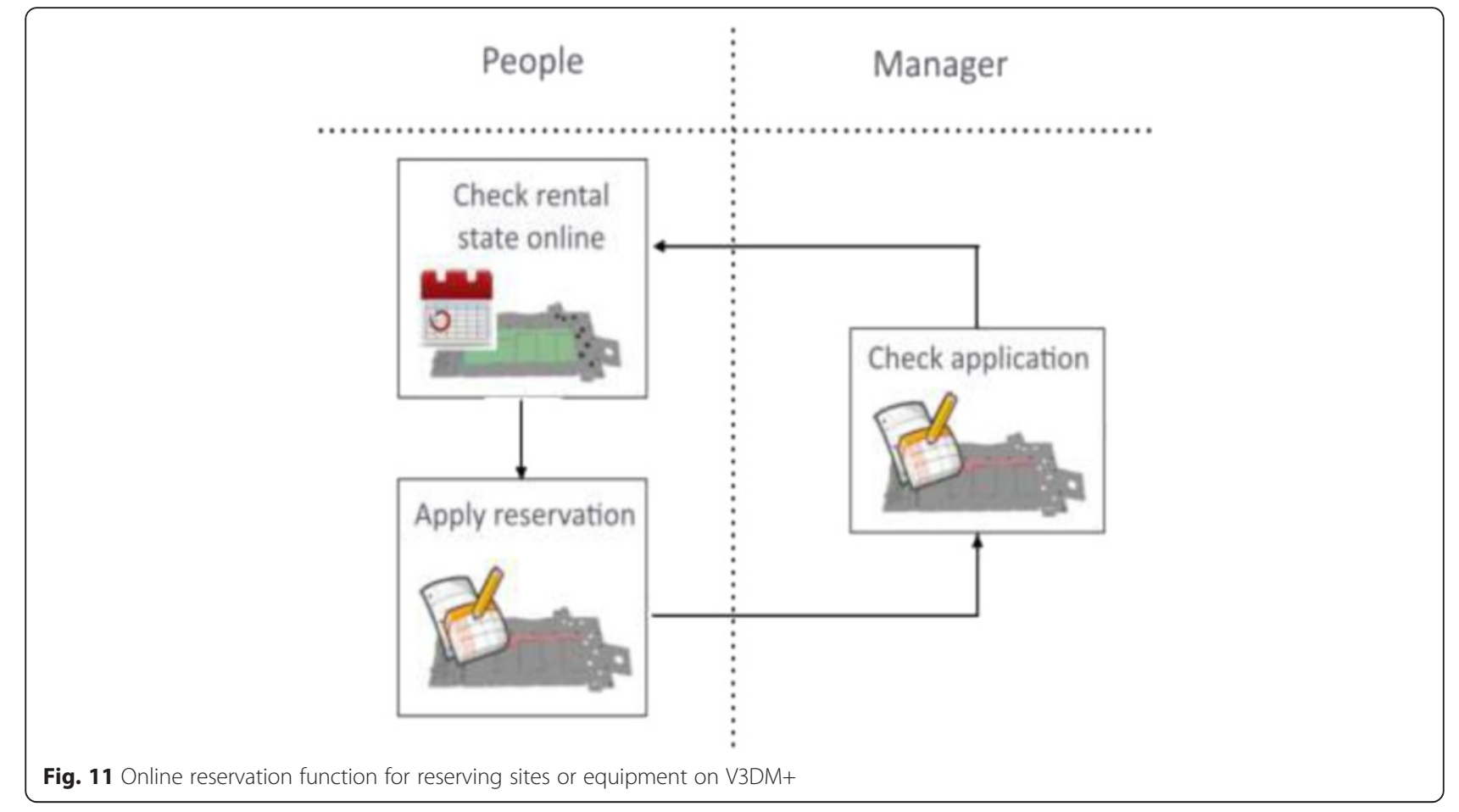

library for a user to transform the models into the same file format.

\section{A web-based platform with an intuitive user interface}

Unlike other commercial software, V3DM+ provides a web-based platform that does not require users to invest in authorized software or employ professionals. The intuitive user interface can elevate the willingness of users to implement this system.

\section{A multifunctional system for both managers and maintenance personnel}

$\mathrm{V} 3 \mathrm{DM}+$ provides three main functions: data browsing, issue discussion, and task assignment. A manager can

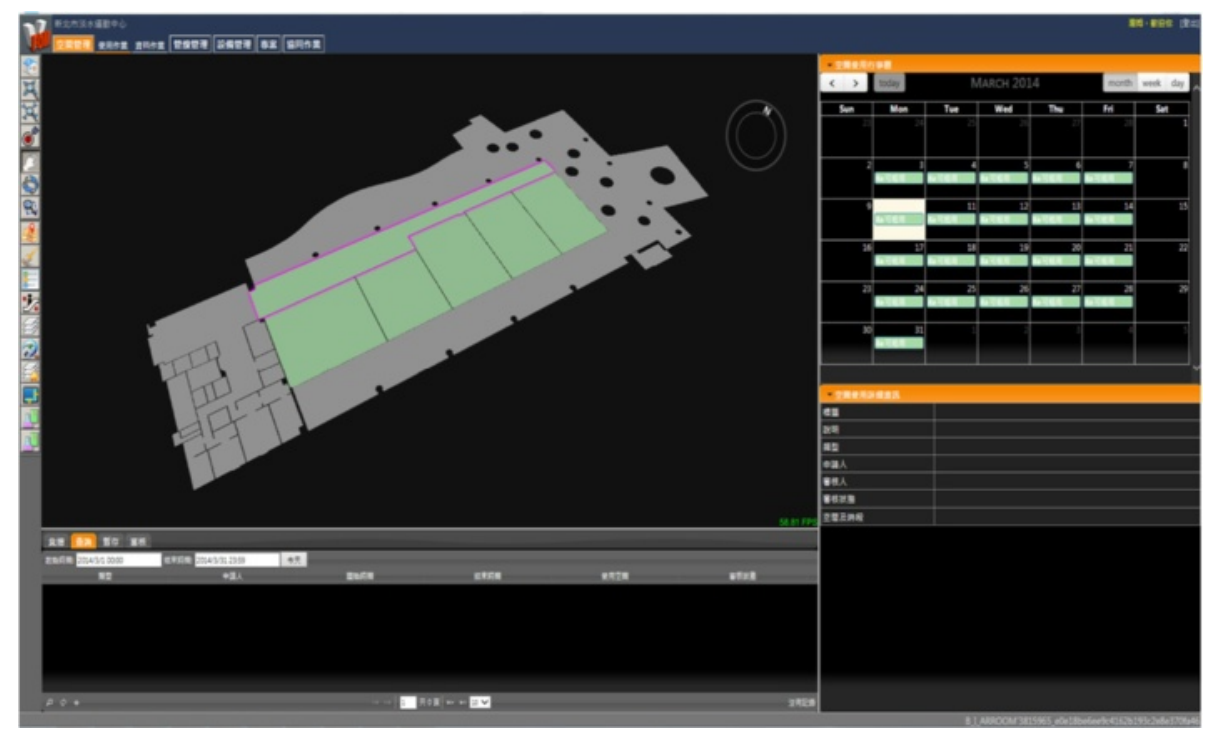

Fig. 12 Online reservation for renting equipment or space by logging in to V3DM+ 


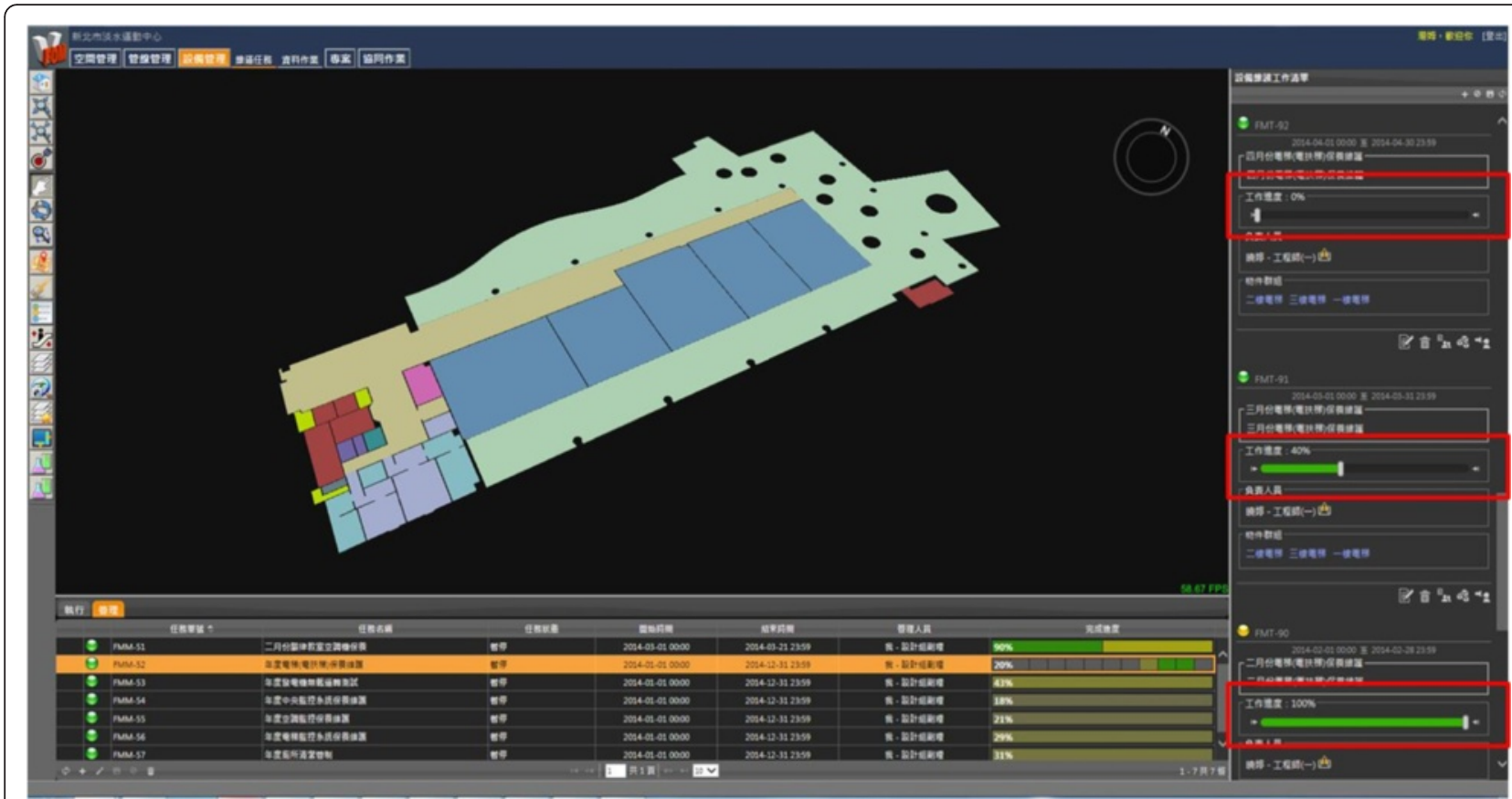

Fig. 13 Inspectors and cleaning staff upload the task progress to V3DM+ for the manager's confirmation

browse 3D models and information data on the system and initiate a discussion online when a problem is detected. In case of regular inspection of facilities or maintenance of broken facilities, a manager can directly assign maintenance tasks to appropriate personnel. In addition, the personnel can update a progress report on the same system.

\section{Enhancement of comprehension of information via visualization}

The data are visualized to provide users with complete and clear information. The issues or tasks can be connected to a realistic 3D model to enhance comprehension for appropriate users.

\section{Limitations}

Even though V3DM+ can support several types of FM issues, there are still some limitations to overcome, as mentioned below.

\section{Low data integrity for existing projects}

When implementing V3DM+ into an existing project, we can only use completed construction reports and existing $3 \mathrm{D}$ models as a data source. Therefore, it is difficult to ensure the accuracy and integrity of the data source.

\section{Manual importing of data}

V3DM+ does not currently include a feature for automatic importing of data. Instead, users must use an API library to manually import data into the system.

\section{Different demands of the system functions}

Different management practices lead to different demands of the system functions. Therefore, the functions of the V3DM+ base need to be adjusted according to users' management demands.

\section{Data importing standard}

From the findings of the accessibility analysis of the TSSC, we found out that it is difficult to ensure the integrity of inherited data. Therefore, we developed a data importing standard for using V3DM+. In this standard, the data may be classified into three main categories: architecture, MEP, and operational facilities. Each category has different importing standards in the three phases, design, construction, and management. For example, the model for architecture-related data, which will remain unchanged in the operational phase, is simplified to avoid excessive and unnecessary data (Table 2). However, the operation-related data should provide a complete model and detailed manufacturing information so that managers can easily find the maintenance manufacturer in case of a facility breakdown (Table 3).

\section{Conclusion}

In this study, we designed and implemented an innovative system, V3DM+, for facility management. This system provides an interactive collaboration platform for the maintenance and operation phase. Managers of a building can browse through the data, initiate discussions, or assign maintenance tasks directly in V3DM+. 
Table 2 Architecture-related model, simplified to avoid excessive and unnecessary data

\begin{tabular}{|c|c|c|c|c|c|}
\hline \multicolumn{2}{|c|}{ Category } & Architecture & Detail & \multicolumn{2}{|l|}{ Foundation } \\
\hline \multicolumn{2}{|c|}{ Name } & \multicolumn{4}{|l|}{ Footing } \\
\hline \multicolumn{2}{|c|}{ Data generation phase } & Design & Construction & Management & Notes \\
\hline \multicolumn{2}{|c|}{ ID } & $\mathrm{V}$ & $\mathrm{V}$ & $\mathrm{V}$ & \\
\hline \multicolumn{2}{|c|}{ Materials } & $\mathrm{V}$ & $\mathrm{V}$ & $\mathrm{V}$ & \\
\hline \multirow{7}{*}{$\begin{array}{l}\text { Modeling } \\
\text { information }\end{array}$} & Length & V & V & $\mathrm{V}$ & \\
\hline & Width & V & V & V & \\
\hline & Height & V & V & V & \\
\hline & Elevation & V & V & V & \\
\hline & Area & - & - & - & \\
\hline & Volume & V & V & V & \\
\hline & Weight & V & V & V & \\
\hline \multirow{4}{*}{ Manufacturing } & Manufacturer & - & - & - & \\
\hline & $\begin{array}{l}\text { Warranty } \\
\text { Date }\end{array}$ & - & - & - & \\
\hline & $\begin{array}{l}\text { Maintenance } \\
\text { Manufacturer }\end{array}$ & - & - & - & \\
\hline & Price & - & - & - & \\
\hline \multirow{5}{*}{ Attached files } & Drawings & V & V & V & \\
\hline & Standards & V & V & V & \\
\hline & Pictures & - & V & V & \\
\hline & Catalog & - & - & - & \\
\hline & Manual & - & - & - & \\
\hline
\end{tabular}

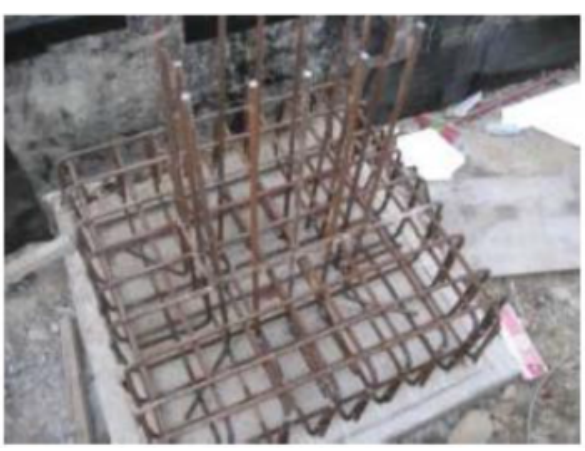

Picture Example

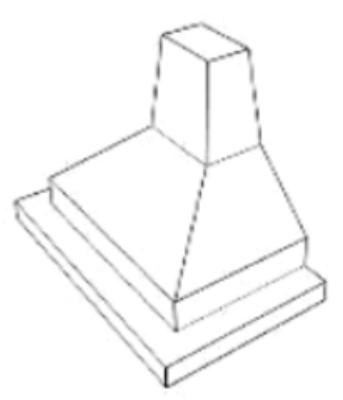

Model Example 
Table 3 Operation-related data is provided as a completed model with detailed manufacturing information

\begin{tabular}{|c|c|c|c|c|c|}
\hline \multicolumn{2}{|c|}{ Category } & MEP & Detail & \multicolumn{2}{|l|}{ Water pipeline } \\
\hline \multicolumn{2}{|c|}{ Name } & \multicolumn{4}{|c|}{ Cold water pipeline } \\
\hline \multicolumn{2}{|c|}{ Data generation phase } & Design & Construction & Management & Notes \\
\hline \multicolumn{2}{|c|}{ ID } & - & $\mathrm{V}$ & $\mathrm{V}$ & \\
\hline \multicolumn{2}{|c|}{ Materials } & V & $\mathrm{V}$ & $\mathrm{V}$ & \\
\hline \multirow{7}{*}{$\begin{array}{l}\text { Modeling } \\
\text { information }\end{array}$} & Length & V & $\mathrm{V}$ & $\mathrm{V}$ & \\
\hline & Width & V & $\mathrm{V}$ & V & \\
\hline & Height & V & $\mathrm{V}$ & $\mathrm{V}$ & \\
\hline & Elevation & V & $\mathrm{V}$ & $\mathrm{V}$ & \\
\hline & Area & - & - & - & \\
\hline & Volume & - & - & - & \\
\hline & Weight & - & - & - & \\
\hline \multirow{4}{*}{ Manufacturing } & Manufacturer & - & $\mathrm{V}$ & $\mathrm{V}$ & \\
\hline & $\begin{array}{l}\text { Warranty } \\
\text { Date }\end{array}$ & - & $\mathrm{V}$ & $\mathrm{V}$ & \\
\hline & $\begin{array}{l}\text { Maintenance } \\
\text { Manufacturer }\end{array}$ & - & V & $\mathrm{V}$ & \\
\hline & Price & - & - & - & \\
\hline \multirow{5}{*}{ Attached files } & Drawings & V & $\mathrm{V}$ & V & \\
\hline & Standards & V & V & V & \\
\hline & Pictures & - & $\mathrm{V}$ & $\mathrm{V}$ & \\
\hline & Catalog & - & $\mathrm{V}$ & $\mathrm{V}$ & \\
\hline & Manual & - & $\mathrm{V}$ & $\mathrm{V}$ & \\
\hline
\end{tabular}

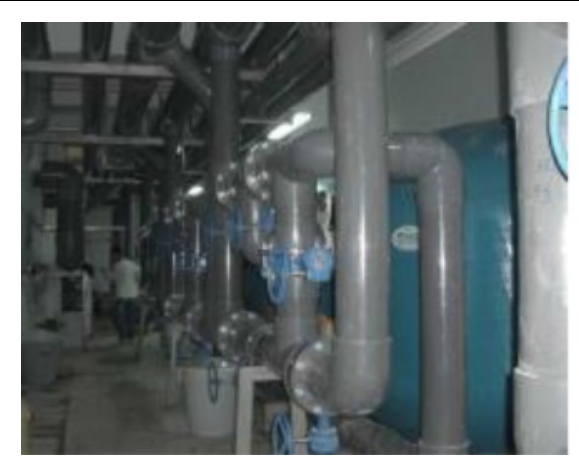

Picture Example 
For the users to manage facilities without the need to use authorized software, a data arrangement module was developed, in which an API library is used for importing models built using different BIM tools. For connecting all objects in the models with their related information data, specific IDs were assigned to both the object and its related data. In addition, a game engine was applied for presenting a model in a realistic 3D rendering environment. Using the game engine to display the special information, the user can browse through the model intuitively in a visual way.

Through an accessibility analysis, we verified that the system can be implemented in a real project, and the results confirmed that V3DM+ is an effective tool for facility management. Users can import data into V3DM+ regardless of the file format. Using $\mathrm{V} 3 \mathrm{DM}+$ to manage facilities is easier than using existing BIM tools. The analysis results showed that $\mathrm{V} 3 \mathrm{DM}+$ has a great potential to elevate the effectiveness and reduce operational maintenance costs for buildings In future work, automatic importing and presentation of data will be realized by implementing a data transformation module.

\section{Competing interests}

The authors declare that they have no competing interests.

\section{Authors' contributions}

WLL, JRJ and JYS together developed the system and conducted the accessibility experiment. CHY drafted the manuscript, analyzed the result of accessibility experiment, and did the literature review. MHT assisted the literature review and analyzed the result of accessibility experiment. WLL offered suggestion and guidance to the research. All authors read and approved the final manuscript.

\footnotetext{
Author details

'BIM Integration Center, CECI Engineering Consultants, Inc., Taipei, Taiwan. ${ }^{2}$ Center for Weather Climate and Disaster Research, National Taiwan. University, Taipei, Taiwan. ${ }^{3}$ Department of Civil Engineering, National Taiwan University, Taipei, Taiwan.
}

Received: 6 December 2015 Accepted: 11 February 2016

Published online: 24 February 2016

\section{References}

Becerik-Gerber, B., Jazizadeh, F., Li, N., \& Calis, G. (2012). Application areas and data requirements for BIM-enabled facilities management. Journal of Construction Engineering and Management-Asce, 138(3), 431-442.

buildingSMART International Ltd. (2015). My Software and IFC. http://www. buildingsmart-tech.org. Accessed 28 Nov 2015.

Chen, C. P., Lu, Q., \& Phil, M. (2015). A review of the efforts and roles of the public sector for BIM adoption worldwide. Journal of Information Technology in Construction, 20,442-478.

Chen, H. T., Wu, S. W., \& Hsieh, S. H. (2013). Visualization of CCTV coverage in public building space using BIM technology. Visualization in Engineering, 1, 5. doi:10.1186/2213-7459-1-5.

East, WE. (2007) Construction operations building information exchange (COBIE) requirements definition and pilot implementation standard. Construction Engineering Resarch Laboratory (CERL), 195. https://www.researchgate.net/ publication/235049209_Construction_Operations_Building_Information_ Exchange_COBIE_Requirements_Definition_and_Pilot_Implementation_ Standard.

Eastman, C., Teicholz, P., Sacks, R., \& Liston, K. (2008). BIM handbook: A guide to building information modeling for owners, managers, designers, engineers, and contractors (2nd ed.). Hoboken, NJ: Wiley.
Edwards, G., Lee, H., \& Wang, B. (2015). BIM based collaborative and interactive design process using computer game engine for general end-users. Visualization in Engineering, 3, 4. doi:10.1186/s40327-015-0018-2.

Gallaher, M. P., O'Connor, A. C., Dettbarn, J. L., \& Gilday, L. T. (2004). Cost analysis of inadequate interoperability in the U.S. capital facilities industry. Gaithersburg, Maryland: NIST.

Lee, C. H., Tsai, M. H., \& Kang, S. C. (2014). A visual tool for accessibility study of pipeline maintenance during design. Visualization in Engineering, 2, 6. doi:10.1186/s40327-014-0006-y.

Lee, W., Kang, S., Moh, R., Wu, R., Hsieh, H., \& Shu, Z. (2015). Application of BIM coordination technology to HSR Changhua station. Visualization in Engineering, 3, 5.

NIST. (2007). National Building Information Modeling Standard Version 1 - Part 1: Overview, Principles, and Methodologies. National Institute of Building Science. http://www.1stpricing.com/pdf/NBIMSv1_ConsolidatedBody_ Mar07.pdf

Petri, I., Li, H., Rezgui, Y., Yang, C., Yuce, B., \& Jayan, B. (2014). A HPC based cloud model for real time energy optimization, Enterprise Information Systems. UK: Taylor \& Francis.

Scarponcini, P. (1996). Time for an integrated approach to facility management. Journal of Computing in Civil Engineering, 10(1), 3.

Singh, V., Gu, N., \& Wang, X. (2011). A theoretical framework of a BIM-based multi-disciplinary collaboration platform. Automation in Construction, 20, 134-144.

Tsai, M. H., Kang, S. C., \& Hsieh, S. H. (2014a). Lessons Learnt from Customization of a BIM Tool for a Design-Build Company. Journal of the Chinese Institute of Engineers, 37(2), 189-199.

Tsai, M. H., Mom, M., \& Hsieh, S. H. (2014b). Developing Critical Success Factors for the Assessment of BIM Technology Adoption: Part I. Methodology and Survey. Journal of the Chinese Institute of Engineers, 37(7), 845-858.

Vanlande, R., Nicolle, C., \& Cruz, C. (2008). IFC and building lifecycle management. Automation in Construction, 18, 70-78.

Wetzel, E. M., \& Thabet, W. Y. (2015). The use of a BIM-based framework to support safe facility management processes. Automation in Construction, $60,12-24$.

YouBIM, LLC. (2015). About YouBIM. http://www.youbim.com/about-youbim.html. Accessed 25 Jan 2016

Yu, K., Froese, T., \& Grobler, F. (2000). A development framework for data models for computer-integrated facilities management. Automation in Construction, 9, 145-167.

\section{Submit your manuscript to a SpringerOpen ${ }^{\circ}$ journal and benefit from:}

- Convenient online submission

- Rigorous peer review

- Immediate publication on acceptance

- Open access: articles freely available online

- High visibility within the field

- Retaining the copyright to your article

Submit your next manuscript at $>$ springeropen.com 